\title{
Simulation in management accounting and management control: editorial
}

\author{
Paolo Pellizzari $^{1}$. Friederike Wall ${ }^{2}$
}

(C) Springer-Verlag Berlin Heidelberg 2015

This special issue of the Journal of Management Control focuses on simulation in management accounting and management control. Since simulation is anything but new in the domain of management and business administration, and, hence, some remarks for motivating the subject of this special issue appear appropriate. Therefore, it is helpful to distinguish between two major ways to make use of simulation methods in the field of management accounting and control.

First, simulation methods are widely used as powerful tools within management accounting and management control: for example, the use of simulation for evaluating operational and financial risks has a long tradition, simulation helps to estimate errors incorporated in accounting numbers; and in a nutshell, what-if analyses and sensitivity analyses are simulative approaches for figuring out the effects of changes in parameters on relevant performance measures (e.g. Zannetos 1963; Economos 1969; Chan 1996; Leitner 2012). Keeping this in mind, simulation could be supposed to become even more relevant within management accounting and control since the need for tools reasonably increases which are capable to deal with uncertainty, complexity and dynamics.

Second, simulation can serve as a research method in the domain of management accounting and management control, and, in this respect, the picture is rather disparate: on the one hand, there is some evidence that, so far, simulation-based research in management accounting and control is of minor relevance, particularly, in comparison against the predominant methods like closed-form analytical modelling, empirical research and conceptual development of frameworks (Hesford et al. 2007). On the

\footnotetext{
Paolo Pellizzari paolop@unive.it

1 Università Ca' Foscari Venezia, Venice, Italy

2 Alpen-Adria-Universität Klagenfurt, Klagenfurt, Austria
} 
other hand, simulation as a research method provides the potential to analyze complex and emergent phenomena that incorporate a multitude of interrelated issues which may lead to intractable analytical models and which would be particularly difficult to control in empirical research. Moreover, in the last decades some simulation approaches have been developed which allow for investigating complex organizations and, by that, could, for example, complement those research efforts in management accounting and control based on normative principal agent theory (Wall 2014).

This special issue addresses both perspectives and, hence, comprises papers which introduce research on simulation as a tool in management accounting and control as well as papers which reflect on or make use of simulation as a research method in this domain. It is a great pleasure for us to introduce this double special issue with seven papers by two Austrian, five German, four Italian researchers and one scholar from the US.

The start is made by a position paper of Eva Labro on simulation-based methods in the field of accounting research. Beginning with the finding that simulation-despite its undoubted potential — is rarely used as a research method in accounting, the paper addresses major difficulties encountered with simulation-based research in accounting. Among these obstacles are, for example, problems in designing the models and appropriately calibrating parameters in order to achieve external validity, but also the fact that the research community in accounting is rather unfamiliar with simulation-based methods. The paper gives advice to mitigate the difficulties discussed and, hence, provides valuable guidance to those accounting researchers which use simulation-based methods.

The illustrative overview provided by Stephan Leitner and Friederike Wall reports on simulation-based research efforts related to management accounting systems, organizational control mechanisms for managerial decision-making, and strategy development and implementation. Interestingly enough, only a comparably small number of these research efforts is published in journals primarily related to the domain of management accounting and control. From this survey the paper concludes that simulation-based method could help to gain a deeper understanding of the interactions between the micro- and the macro-layer of the control mechanisms employed in organizations as well as figure out the emergent properties of management control systems.

Given the major obstacles of simulation-based research in the field of accounting as discussed in Eva Labro's position paper, Sina Hocke, Matthias Meyer andIris Lorscheid suggest the establishment of standards in simulation-based research methods as a promising approach to foster the acceptance of simulation research. In particular, the authors propose to apply a set of principles for the design of experiments (DOE principles) and demonstrate the application of these principles in a "case study" in the field of cost allocation: the illustrative simulation study compares the accuracy of the direct to the reciprocal method of cost allocation for different company types. Hence, the takeaways of the paper are twofold: it further substantiates the contributions of simulation research in the domain of cost accounting and demonstrates how the understanding and communication of simulation-based research could be enhanced by standardization. 
Using a simulation-based approach Graziano Coller and Paolo Collini investigate an "evergreen" in cost accounting, i.e. the questionable optimality of full-cost pricing. In particular, the authors suppose two factors to be relevant for the (non-)optimality of full-cost pricing — and, thus, to allow for explaining the inconsistent findings of prior research: the dynamics of the pricing mechanisms and the level of demand variability. The results indicate that in case of static demand full-cost pricing performs rather good, providing virtually no economic loss against the optimum, and, moreover, with the advantage requiring less information than marginal cost pricing. However, simulation results suggest that with stochastic demand full-cost pricing is likely to evoke repelling dynamics and economic losses.

The paper of Robert Rieg provides another example for the use of simulation research in the very center of the domain of the Journal of Management Control: the paper studies short-term orientation and myopia as they are commonly suspected to come along with value-based management on the site of both investors and managers. In particular, the study employs System Dynamics as simulation approach and investigates whether short-termism and myopia emerge endogenously and which countermeasures could effectively mitigate these side effects of value based management. A striking result is that not deficiencies of managers' or investors' behavior cause short-term orientation but the concept of shareholder value itself.

With the paper of Federico Cosenz and Lidia Noto the special issue turns to research on simulation used as tool within management accounting and management control. As such the authors propose simulation-based methodologies to support entrepreneurial learning processes enabling managers to discover crisis symptoms and weak signals of change more effectively with a special focus on small and medium-sized firms. In particular, the Dynamic Performance Management (DPM) approach, based on System Dynamics, is introduced and illustrated in a case study which allows entrepreneurs to measure and manage business performance according to a learning-oriented perspective on the system's behavior.

While considerable research efforts have been taken to develop powerful simulation tools for practical use in management accounting and control-as the paper of Cosenz and Noto exemplarily shows - an interesting question whether simulation actually is used by management accountants and controllers. The paper of Cathérine Grisar and Matthias Meyer is related to this research question. In particular, they empirically investigate the adoption of Monte-Carlo simulation in controlling departments of companies in German-speaking countries and analyze the effects of contextual factors on the intensity of simulation use. The manifold of results suggest that-while currently the adoption of Monte Carlo simulation in controlling departments is rather low-there is considerable evidence for increasing future use. 
To honour the great expertise, support and effort of our reviewers in guiding authors to further improve their papers, the editors of the Journal of Management Control voted for JoMaC's Best Reviewer Award in 2014. This year the editors of JoMaC are proud to honour the following colleagues:

Best reviewer award 2014: Martin Hiebl, Johannes Kepler University, Linz, Austria

Runners up are: Gerhard Leitner, Alpen-Adria-Universität, Klagenfurt, Austria

Klaus Derfuss, Fernuniversität Hagen, Germany

Christian Ott, European University Viadrina, Frankfurt(O), Germany

The editors of JoMaC appreciate the great, continuous support and their-often leisure-time dedicated to our journal.

We would like to express our gratitude to our authors and reviewers for all the work and effort they invested in this special issue and, of course, we hope that all of the readers will enjoy this volume. Moreover, we hope that this special issue contributes to shed some new light on the current state, the potential as well as the challenges of simulation in the domain of management accounting and control and that it provides some ideas for future research in this interesting field.

The guest editors of this special issue

Paolo Pellizzari

Friederike Wall

\section{References}

Chan, K. H. (1996). Estimating accounting errors in audit sampling: extensions and empirical tests of a decomposition approach. Journal Accounting Auditing Finance, 11(2), 153-161.

Economos, A. M. (1969). A financial simulation for risk analysis of a proposed subsidiary. Management Science, 15(12), B-675-B-682.

Hesford, J. W., Lee, S.-H. S., Van der Stede, W. A., \& Young, S. M. (2007). Management accounting: a bibliographic study. In C. S. Chapman, A. G. Hoopwood, \& M. D. Shields (Eds.), Handbook of management accounting research (1st ed., pp. 3-26). Amsterdam: Elsevier.

Leitner, S. (2012). A simulation analysis of interactions among intended biases in costing systems and their effects on the accuracy of decision-influencing information. Central European Journal of Operations Research 1-26. doi:10.1007/s10100-012-0275-2

Wall, F. (2014). Agent-based modeling in managerial science: an illustrative survey and study. Review of Managerial Science 1-59. doi:10.1007/s11846-014-0139-3

Zannetos, Z. S. (1963). Mathematics as a tool of accounting instruction and research. Accounting Review, $38(2), 326$. 